\title{
Planning for interprofessional change in primary health care: exploring the use of the Interprofessional Resource Centre
}

This article was published in the following Dove Press journal:

Advances in Medical Education and Practice

13 May 2013

Number of times this article has been viewed

\section{Christine Patterson' \\ Heather Arthur ${ }^{1,2}$ \\ Gladys Peachey' \\ Julie Vohra' \\ David Price ${ }^{3}$ \\ Dave Pearson ${ }^{4}$ \\ Rob Mariani ${ }^{5}$}

'School of Nursing, Faculty of Health Sciences, McMaster University, Hamilton, ON, Canada; ${ }^{2}$ Heart and Stroke Foundation of Ontario/ Michael G DeGroote Endowed Chair in Cardiovascular Nursing Research, McMaster University, Hamilton, ON, Canada; ${ }^{3}$ Department of Family Medicine, McMaster University, Hamilton, ON, Canada; ${ }^{4}$ Central West Local Health Integration Network, Brampton, ON, Canada; ${ }^{5}$ Ascentum Consulting, Ottawa, ON, Canada
Correspondence: Christine Patterson McMaster University, Faculty of Health Sciences, School of Nursing, HSC-2J2 IB, I 200 Main St West, Hamilton, ON L8N 3Z5, Canada Tel +l 9055259140 , ext 22304 Fax + I 9055700667

Email cpatter@mcmaster.ca
Importance: Resources to support change are needed for solo practitioners who are transitioning to family health teams (FHTs) which involve multiple health disciplines working together to provide team-based care.

Objective: The purpose of this project was: (1) to explore the use of an online resource, the Interprofessional Resource Centre (IRC), when planning for interprofessional change and; (2) to explore the experience of planning interprofessional change.

Design and setting: Six FHTs organized under the structure of one Local Health Integrated Network (LHIN) in Ontario, Canada.

Intervention: Participants in six FHTs were directed to the IRC to support planning interprofessional change. In addition, two of the six FHTs participated in pilot site meetings with investigators where they received in-person support to apply the information from the IRC to an interprofessional activity.

Results: Pilot site participants reported the IRC was useful for planning, but they cited lack of time to use it as a key barrier. When planning for interprofessional change, providers experienced challenges with physician buy-in and team dynamics. As a strategy for change, providers would like to learn from other FHTs who have experienced success with interprofessional change; at the LHIN level, they saw a need for more educational opportunities. Participation was found to be low among those only receiving online support.

Conclusion and relevance: Based on the results of the study, it appears that online resource centers do have some value in knowledge translation when combined with in-person meetings. In exploring the planning of interprofessional change in primary health care teams, it was found that buy-in with physicians is a key challenge.

Keywords: online, knowledge transfer, family health teams, team-based care, supporting change, buy-in

\section{Introduction}

In Ontario, family health teams (FHTs) are organized under the administrative structure of Local Health Integration Networks (LHINs) that oversee the funding, planning and integration of health care services based on local needs. ${ }^{1}$ Organizations within these networks are being challenged to review how disciplines work together and the level of interprofessional practice required for the desired patient outcomes within their services to the community. Resources to support organizational change for interprofessional care are needed as health care providers are transitioning from more traditional health care arrangements into ones that require partnership with multiple health disciplines. ${ }^{2}$ One resource available to support interprofessional change is the Interprofessional Resource Centre (http://www.interprofessionalresourcecentre.ca). 
This website presents evidence-based information regarding advancing interprofessional care through creating supportive environments, interprofessional practice, and education. ${ }^{3}$

Transition to interprofessional care within organizations requires carefully planned strategies based on an understanding of the determinants and processes that influence interprofessional education and practice. ${ }^{4,5}$ At the team level, the interprofessional practice leading to care is ultimately the result of strategic planning within a supportive administrative environment. An important component of successful strategic planning within the organization is therefore, application of the appropriate information to achieve goals, known as knowledge translation. The Canadian Institutes of Health Research (CIHR) defines knowledge translation as:

... a dynamic and iterative process that includes synthesis, dissemination, exchange and ethically-sound application of knowledge to improve the health of Canadians, provide more effective health services and products and strengthen the health care system (p. 1). ${ }^{6}$

According to the CIHR definition, the Interprofessional Resource Centre (IRC) is a tool that can facilitate the process of knowledge transfer.

In busy clinical environments, the need for readily available information can be an asset to planning efficiently and within acceptable timeframes. Using technology has been described as an important component in knowledge translation, given its easy accessibility and availability., Health providers are able to log on to websites at a time and location that is suited to them, as well as being able to go back to the resource to review it as often as desired, making the resource both cost-effective and convenient. Using online resources also allows for information to be disseminated to a large number of users, regardless of geographic location, as in the case with LHINs, where FHTs can be located in different physical locations. The IRC, as an online resource, is therefore considered an enabler in the knowledge transfer process as it allows for easy exchange of synthesized knowledge as providers plan interprofessional change, regardless of location., ${ }^{2,9}$

During change, a common barrier is dealing with resistance from individuals who are not willing or ready to accept change. Organizations can deal with resistance by providing supportive resources, such as the IRC, and supporting communication initiatives through meetings. ${ }^{10-12}$ Selecting key individuals to participate in planning change has been cited as a facilitator for change planning. ${ }^{12}$ It was predicted that engaging interested health providers through meetings in association with the use of the IRC as a resource would be beneficial in moving organizations toward interprofessional practice within this LHIN.

\section{Purpose}

The purpose of this project was: (1) to explore the use of the IRC when planning for interprofessional change and; (2) to explore the experience of planning interprofessional change.

\section{Methods}

\section{Sample}

Using opportunistic sampling, within one LHIN, seven FHTs were invited to participate in this project; one declined, leaving six participating FHTs. The FHTs are comprised of administrators and interprofessional primary health care providers such as: physicians, nurses, nurse practitioners, registered dietitians, pharmacists, and social workers, to name a few. Pilot sites were assigned opportunistically for their openness to interprofessional practice and their willingness to explore it further within their current operating programs. Participants in the pilot site meetings, and eventually the focus group, were chosen by the leadership of the FHTs because of their involvement in a program of interest or because they were already working together as a team. The pilot sites received a facilitated intervention through supportive meetings using the IRC. The non-pilot sites were self-directed in that they were provided information about the IRC online and were required to use this resource in generating their ideas about their experience with interprofessional practice without any other supports.

\section{Knowledge transfer tool}

The IRC is unique among other online tools in that it is a stepwise approach to supporting an organization's effort in advancing interprofessional practice and education. The overarching framework that guided the content development of the IRC was the five stages of organizational innovation, as defined by Rogers (2003). ${ }^{13}$ The information of the IRC is organized into six steps: preparing a supportive environment, committing to organizational champions, examining patient care services, interprofessional change, developing preceptorships, and evaluation. ${ }^{14}$ For organizations and/or teams considering moving to interprofessional practice and education, the six steps of the IRC should be reviewed in a stepwise fashion to guide their development. For organizations/teams who are more advanced in terms 
of interprofessional practice and education, the IRC can be used to address specific questions. A full explanation of the development of the IRC has been reported earlier. ${ }^{14}$

\section{Data collection and analysis}

The study sought to describe the use of the IRC and providers' perspectives on planning for interprofessional change using multiple avenues. For the pilot sites, data were collected during a focus group. Both pilot and non-pilot sites offered additional narrative information through an online forum, as well as a summative survey. The rationale for using a variety of data collection methods was to provide opportunity for all participants in the pilot and non-pilot sites to provide insights into their experience with planning interprofessional change. Data collection was completed over the course of 1 year.

\section{Meetings}

Site meetings were held at the two pilot sites to support providers in using the IRC to plan interprofessional change. Three to four site meetings took place over the following year. The purpose of the site meetings was to: (1) define a goal for improving interprofessional practice in their organization; (2) formulate a plan to implement changes; (3) explore how the providers could use the IRC to guide the planning process; and (4) explore their perceptions of the experience.

\section{Focus groups}

At the conclusion of the site meetings, two focus groups were conducted (one at each of the pilot sites) with the committee of interprofessional providers to explore the experience of planning for interprofessional change using the IRC. The focus group question guide, which identified topic questions as well as follow-up probes, was designed using the framework of the appreciative 4-D cycle, which includes the following phases: discovery, dream, design, and destiny. ${ }^{15}$ During the focus group, participants were asked to describe the experience of defining their goal as well as their successes and challenges during planning and how the IRC was used in the process. Participants were also asked about what possibilities they saw for interprofessional practice at their FHT in the future and how the IRC may or may not be helpful moving forward.

The focus groups were facilitated by the principal investigators. The content of the focus group was audiotaped and later transcribed verbatim; all personal identifiers were removed to ensure anonymity. Each focus group lasted approximately 60 minutes. Summaries were created of the main topics that were discussed in the focus group and later reviewed by the participants to ensure trustworthiness of the data. Ethics approval was not required for this study since it was an educational project which involved health care providers.

Focus group data were analyzed using qualitative description. Sandelowski ${ }^{16}$ describes qualitative description as a valuable approach when straight descriptions of phenomena and answers of relevance to practitioners and policy makers are desired. ${ }^{16}$ Milne and Oberle describe this method as:

... a stand-alone method that affords a comprehensive summary of human experience without an in-depth level of interpretation (p. 413). ${ }^{17}$

This method is recommended for the simple structure of descriptive studies as it does not involve extensive interpretation of the data. ${ }^{16}$

Three reviewers were involved in the preliminary analysis of the focus group data. Two reviewers were involved in administering the focus group, whereas one reviewer was not involved in the data collection process but had knowledge of administration, leadership, and interprofessional practice. These three reviewers read and reread the data independently and assigned preliminary codes to meaningful sentences or phrases in the data. There was general agreement surrounding coding among the reviewers; any disagreements were resolved through discussion. Once consensus was reached among the three reviewers, one additional reviewer, who was also involved in administering the focus groups, reviewed the codes independently. A meeting was held with the four reviewers to reach a final consensus and collapse the codes into overall themes.

\section{Online forum}

Over the course of the project, all participating FHTs received three electronic newsletters, directing them to an online forum. The newsletters served two purposes: (1) to encourage providers to post their ideas about interprofessional topics important to planning change in organizations/teams; and (2) to provide project updates. Newsletter topics included interprofessional practice, leadership, and communication. All posted comments were reviewed and analyzed using the same methods described for the focus group data.

\section{Summative survey}

Near the end of the study, an online survey was circulated to all study participants. The survey examined the use of the IRC as well as provider's strategies, challenges, and 
questions surrounding interprofessional practice. The content of the survey was developed based on our observations from the pilot site meetings, the change process as outlined on the IRC, as well as related literature on knowledge translation barriers..$^{3,18-20}$ The survey had four categories: (1) demographics; (2) strategies at the LHIN and FHT levels to achieve interprofessional practice; (3) questions for achieving interprofessional care in the LHIN; and (4) the use of the IRC as a knowledge translation tool. The survey was reviewed by the investigating team and a member of the LHIN advisory board for face validity; all suggestions for improvement were incorporated. Following accepted survey methods to ensure participant response, notices were sent in advance to inform participants of the upcoming survey and included details outlining why participant responses were important as well as ensuring confidentiality of responses. Two reminders were sent after the initial mailing. ${ }^{21}$

Quantitative survey results were summarized using frequencies. Results were reviewed and tabulated in rank order in terms of respondents endorsing important or very important ( 4 or 5 on a 5 -point scale). Based on the participants' ranking, there was a considerable drop in the rating of importance after the $75 \%$ level for sections of the survey concerning strategies and challenges to interprofessional practice and questions respondents had around interprofessional practice. The section concerning exploring the use of the IRC was completed by half of survey respondents. Based on participants' ranking for this section, the cut-off was lower, ranging from 50\%-27\%. Comments were summarized narratively.

\section{Results}

\section{Pilot site demographics - site} meetings and focus group

Site meeting participants were a committee of five to six interprofessional providers and included administrators, physicians, nurse practitioners, nurses, nurse educators, physician assistants, and registered dietitians. These same individuals comprised the focus group participants. This committee represented approximately 25 interprofessional staff at each pilot site.

\section{Participant demographics - summative survey}

The survey was sent to all 96 participants across the six FHTs. Completed surveys were received from 40 respondents (41.7\% response rate), with 20 indicating they participated as a pilot site. Because of stakeholder concerns with confidentiality and privacy, the survey did not track respondents, with respect to which FHT they belonged, limiting the ability to draw comparisons between pilot and non-pilot sites.

Respondents to the quantitative survey were primarily female which was consistent with the composition of the respondents in the pilot sites. Respondents represented various health disciplines and reported a range in both years working in interprofessional practice and level of team functioning (Table 1).

\section{Pilot and non-pilot site differences - online forum}

The primary avenue the study aimed to explore pilot and non-pilot site differences in using the IRC was through the online forum. However, it was found that primarily visitors to the forum spent their time reading information, rather

Table I Participant demographics

\begin{tabular}{|c|c|}
\hline Demographics & n (\%) \\
\hline \multicolumn{2}{|l|}{$\operatorname{Sex}(n=28)$} \\
\hline Male & $4(14.3)$ \\
\hline Female & $24(85.7)$ \\
\hline \multicolumn{2}{|l|}{ Age $(n=30)$} \\
\hline 34 and under & $9(30.0)$ \\
\hline $35-44$ & $8(26.7)$ \\
\hline $45+$ & $13(43.3)$ \\
\hline \multicolumn{2}{|l|}{ Health profession $(n=27)$} \\
\hline Administrator & 7 (25.9) \\
\hline Nurse & $5(18.5)$ \\
\hline Dietitian & $3(I I . I)$ \\
\hline Physician & $3(I I . I)$ \\
\hline Mental health practitioner & $2(7.4)$ \\
\hline Pharmacist & $2(7.4)$ \\
\hline Social worker & $2(7.4)$ \\
\hline Homeopath & I (3.7) \\
\hline Nurse practitioner & I (3.7) \\
\hline Occupational therapist & I (3.7) \\
\hline \multicolumn{2}{|l|}{ Years in IP $(n=23)$} \\
\hline$>1$ & $5(21.7)$ \\
\hline I to 5 & II (47.8) \\
\hline 6 to 10 & $4(I 7.4)$ \\
\hline $10+$ & $3(13.0)$ \\
\hline \multicolumn{2}{|c|}{ Level of team functioning* $(n=29)$} \\
\hline Interdisciplinary & $10(34.5)$ \\
\hline Multidisciplinary & $13(44.8)$ \\
\hline Transdisciplinary & $6(20.7)$ \\
\hline
\end{tabular}

Notes: The $\mathrm{n}$ for each question varies due to missing data. Percents are valid percentages and based on $\mathrm{n}$ for stated question. *The Interdisciplinary team is made up of individuals with knowledge from multiple professions. The Multidisciplinary team allows individuals to apply their knowledge and work autonomously to find solutions with the goal of identifying consistency. The Transdisciplinary team allows members to contribute their own knowledge and collectively determine the best idea or approach.

Abbreviation: IP, interprofessional practice. 
than posting ideas or responding to the posting of others. The forum was visited by a total of 88 people 241 times. While on the website, each visitor spent almost 7 minutes on the site, viewing about eight pages per visit. Returning visitors to the website made up about two-thirds of the traffic.

The majority of comments $(n=9)$ were posted after the first online newsletter was circulated; the second online newsletter generated five comments; and, after the third online newsletter, no comments were posted. It was at this point in the project that the online forum was closed due to lack of participation. The limited number of comments did not allow for analysis of pilot and non-pilot site differences. Additional attempts were made to engage participants in the pilot and non-pilot sites via email communication; however, this also proved unsuccessful.

\section{Use of the IRC}

Based on the focus group data, the IRC was used primarily as a resource for addressing providers' questions about interprofessional culture, communication, team building, and goal setting. A drawback of using the IRC was that respondents desired more practical suggestions, particularly about how to facilitate physician buy-in. A summary of the pros and cons of using the IRC, as summarized from all available focus group data, is presented in Table 2 .

From the summative survey, 20 respondents indicated using the IRC. It was found that the top reason participants

Table 2 Summary of pros and cons of using the IRC

\begin{tabular}{|c|c|}
\hline Pros & Cons \\
\hline $\begin{array}{l}\text { To increase knowledge around what } \\
\text { IP care means, good starting point, } \\
\text { framework, overview of principles. }\end{array}$ & $\begin{array}{l}\text { Not sure how the information } \\
\text { on the IRC applies to me; this } \\
\text { may speak to the need for } \\
\text { background information. }\end{array}$ \\
\hline $\begin{array}{l}\text { As an educational resource to } \\
\text { increase knowledge/assist with } \\
\text { development of IP in an FHT, culture } \\
\text { shift, big-picture issues at practice, } \\
\text { organization, and LHIN level. }\end{array}$ & $\begin{array}{l}\text { Wanted more practical } \\
\text { suggestions, quick points to take } \\
\text { away. Found the information } \\
\text { too general. }\end{array}$ \\
\hline $\begin{array}{l}\text { For assessment of current practice } \\
\text { and identify areas for growth. }\end{array}$ & $\begin{array}{l}\text { Need more information/specific } \\
\text { strategies concerning buy-in. }\end{array}$ \\
\hline To guide decision making/thinking. & $\begin{array}{l}\text { Sometimes difficult to navigate; } \\
\text { many layers. }\end{array}$ \\
\hline $\begin{array}{l}\text { To address IP problems around } \\
\text { communication, team building, and } \\
\text { setting goals. }\end{array}$ & $\begin{array}{l}\text { Need dedicated time to spend } \\
\text { to look through it and apply } \\
\text { information. }\end{array}$ \\
\hline \multicolumn{2}{|l|}{$\begin{array}{l}\text { For suggested interview questions; } \\
\text { for recruitment. }\end{array}$} \\
\hline $\begin{array}{l}\text { For assistance with giving student } \\
\text { feedback. }\end{array}$ & \\
\hline
\end{tabular}

Abbreviations: IRC, Interprofessional Resource Centre; FHT, family health team; LHIN, Local Health Integrated Network; IP, interprofessional practice. did not visit the IRC was lack of time. Barriers to using the IRC most-often cited were lack of time to spend reading information and lack of time needed to use information. The sections of the IRC that were used most frequently were examining patient care services and interprofessional change. The information was used most often to plan a strategy/activity or to assist with decision making (Table 3).

\section{Providers' perspectives surrounding planning for interprofessional change}

From the focus group data, themes of buy-in by physicians, sharing experiences in interprofessional practice, and interprofessional team dynamics emerged. These themes are consistent with the findings of the summative survey which will be discussed later.

\section{Buy-in by physicians}

The idea of buy-in was described as necessary for sustainable change.

I think [the physicians] would probably understand [interprofessional care] whether or not they would buy into it. And that's the thing ... I think that they would have the concept and would be okay with it, but ya, some of them are like buy-in might be a little bit rougher.

If people don't see value in it, unless they see the output is gonna change their life ... [they need] tangible benefits.

I think they all have to be interested in it ... if they think, you know, it's important that we are getting together for an

Table 3 Use of IRC

\begin{tabular}{ll}
\hline Descriptor & \\
\hline Reasons did not visit IRC & $\mathrm{n}(\%)$ \\
Lack of time $(\mathrm{n}=\mathrm{I3})$ & $7(53.8)$ \\
Sections used to get information & Frequent use (\%) \\
Examining patient care services $(\mathrm{n}=2 \mathrm{I})$ & $6(28.6)$ \\
Interprofessional change $(\mathrm{n}=22)$ & $6(27.3)$ \\
How information was used & $\mathrm{n}(\%)$ \\
To plan a strategy/activity $(\mathrm{n}=20)$ & $10(50.0)$ \\
To assist with decision making $(\mathrm{n}=20)$ & $8(40.0)$ \\
Barriers using IRC & Agree $(\%)$ \\
Lack of time to spend reading & $13(59.1)$ \\
information ( $=22)$ & \\
Lack of time needed to use information & $12(54.5)$ \\
$(\mathrm{n}=22)$ & \\
\hline
\end{tabular}

Abbreviation: IRC, Interprofessional Resource Centre. 
hour to talk about it [interprofessional care and practice], they should come as well ... but if there's no physician ... sometimes we can't get anything accomplished because it's something that we need their input.

It was noted that strategic planning may be helpful to guide interprofessional change, but that buy-in by physicians is the overarching issue.

I think there would be value in [strategic planning] it again it would just be same thing getting that buy-in from the physicians to participate in that planning process.

It was noted that leadership would be helpful to build buy-in. The attributes of a desired leader were visionary, knowledgeable, collaborative, and committed. The role of the leader in interprofessional practice was described as having the power to create change. Although the participants noted that a leader could be a member of any health discipline, it was perceived that a physician would be the most effective, since the physician leader would build buy-in with other physicians. Commitment and leadership on the part of physicians was seen as essential to implementing changes to interprofessional practice.

I think [leadership] would have to be from a physician. Ya, I think you need a well-respected physician ... just for the physician buy-in, that would help ... you'd have more buy-in and less resistance if it came from a physician.

\section{Sharing experiences in interprofessional practice}

Providers reported wanting to learn about interprofessional practice through sharing experiences with their colleagues in other FHTs.

Ya ... taking a look and seeing what are other family health teams are doing in terms of interprofessional care and how do they make it work.

This is what they've done and this is how they've done it, and you know they struggled here ... Our team did A, B, $\mathrm{C}$, and D, and this is how we used the IRC and this is what we found worked really well. This is what we really struggled with and then needed to go back and get help on.

No, I think we, looking towards other family health teams you know and their experience I think is, they have a lot to offer so I think it's an interesting avenue to pursue.

\section{Interprofessional team dynamics}

Participants were able to recognize barriers to effective interprofessional team functioning. Although there are many facilitators and barriers that can influence team dynamics, they identified role awareness and linked this to respect for roles, as well as collaboration linking this to communication and time for planning together as a team.

\section{Role awareness}

I think we all need to be respecting more of each other's roles and how we work as a ... well-oiled machine.

So I think the problem is people who've been in independent practices for so long are so used to dealing with everything on their own ... if the patient needs, you know, help with breastfeeding, you're gonna send them to the person who does that and that's their job, or the person that does the diet counseling, that's their job that's all they do, recognizing that other people have strengths and pulling on all those strengths ... role awareness is a big issue.

They [the physicians] don't know that the expertise and the value that our providers bring.

\section{Lack of collaboration}

When discussing decision making at the clinical level, participants described the process as physician dominated, highlighting a need for a more collaborative approach with better communication and more time for planning.

I think that it would be obviously more effective if the people involved were the ones helping to make the decisions

Some of our biggest problems ... (1) is communication and (2) is relationship building

We have to set up everything like clear communication, clear role, clear leadership, everything

The time and you need to actually follow the rules, the steps. Like and it's great to come up with ideas and want to better the team and better interprofessional practice, and get everyone you know involved in better patient care, but the planning and the organization prior to the implementation [is needed]

The results of the summative survey align with the themes that emerged from the focus group data. When responding to questions concerning the strategies and challenges to interprofessional practice, the item rated as most important, for both of these sections, centers around physician leadership to champion and sustain interprofessional practice. This finding was noted when investigating strategies at different organizational levels, 
Table 4 Strategies and challenges to interprofessional practice

\begin{tabular}{|c|c|}
\hline Descriptor & Important* \% \\
\hline \multicolumn{2}{|c|}{ Strategies at LHIN level to achieve interprofessional practice } \\
\hline $\begin{array}{l}\text { Supporting physician leadership in FHTs to } \\
\text { champion and sustain interprofessional care } \\
\text { through funding and resources }(n=40)\end{array}$ & $35(87.5)$ \\
\hline $\begin{array}{l}\text { Having educational opportunities on } \\
\text { interprofessional initiatives }(n=38)\end{array}$ & $31(81.6)$ \\
\hline \multicolumn{2}{|l|}{ Challenges to interprofessional practice } \\
\hline $\begin{array}{l}\text { Physician leadership to champion and sustain } \\
\text { interprofessional practice in the agency }(n=34)\end{array}$ & $27(79.4)$ \\
\hline Managing resistance to change $(n=34)$ & $27(79.4)$ \\
\hline $\begin{array}{l}\text { Leadership that supports the changes taking } \\
\text { place }(n=33)\end{array}$ & $26(78.8)$ \\
\hline Having a strong change leader $(n=34)$ & $26(76.5)$ \\
\hline
\end{tabular}

Note: *Rated 4-5 on a 5-point Likert scale.

Abbreviations: LHIN, Local Health Integrated Network; FHT, family health teams.

including the LHIN level and at the practice or team level (Table 4). At the LHIN level, it was noted that educational opportunities are an important strategy to achieve interprofessional practice. At the practice level, managing resistance to change, having leadership that is supportive of change, and having a strong change leader were indicated as important challenges to interprofessional practice. Providers indicated having questions surrounding motivation and commitment, building buy-in, and creating a strategy for interprofessional care (Table 5).

\section{Discussion}

\section{Experience of planning interprofessional change}

This project had two goals: exploring the use of the IRC and the experience of planning interprofessional change within FHTs. With respect to change, the participants in the pilot sites were able to identify an interprofessional activity, but they had limited ability to progress past initial planning. The predominant reason for lack of progress was related to limited physician buy-in and leadership. The results of the summative survey, which included non-pilot sites as well as pilot sites, found that physician leadership was viewed as important for interprofessional change at the LHIN level and

Table 5 Questions respondents have around IP

\begin{tabular}{ll}
\hline Questions & Important*\% \\
\hline How do you gain motivation and commitment for & $27(84.4)$ \\
implementing interprofessional care? $(\mathrm{n}=32)$ & \\
How do you build buy-in? $(\mathrm{n}=33)$ & $26(78.8)$ \\
How do you create a strategy for interprofessional & $26(78.8)$ \\
care? $(\mathrm{n}=33)$ & \\
\hline
\end{tabular}

Note: *Rated 4-5 on a 5-point Likert scale.

Abbreviation: IP, interprofessional practice. also as a challenge to interprofessional practice at the level of the FHTs. This may indicate that physician leadership is desired during interprofessional change; however, it may not be enacted at the practice level. Researchers, exploring the role of physicians as practice change leaders, found that for the physician-leader role to be successful, it needs to be recognized formally and supported through mentoring, networking, education, and training. ${ }^{22-24}$ Since buy-in and leadership by physicians have been identified as important in interprofessional change within this project, it is suggested that FHTs and LHINs address this issue.

Participants in the pilot sites did have insight into other important barriers for developing interprofessional practice within their FHT. They reported a desire to share experiences with their colleagues in other group practices as a way to determine the best strategies to move forward. They also viewed role awareness, collaboration, and communication as important areas for development. Research supports the use of collaborative learning as a successful change strategy that enables the consideration of context, as well as supporting participants in exploring how best to apply changes. ${ }^{25}$ Collaborative learning has also been found to improve connections among participants and to help participants to see themselves as part of a larger care system. ${ }^{26}$ Additionally, role awareness, collaboration, and communication have been described as key competencies for interprofessional care. ${ }^{27}$

A key difference between strategies for interprofessional change at the LHIN and FHT levels was that, at the LHIN level, having educational opportunities related to interprofessional care was rated as important, but at the FHT level, challenges focused on leadership and change management. This may speak to a need at the system level to build knowledge around interprofessional practice and care. Building knowledge at the organizational level may also act as a support for the challenges noted at the practice level. Similarly, a recent study investigating the successful promotion of interprofessional collaboration included education as a key component. ${ }^{28}$

Important questions around interprofessional care concerned motivation and commitment, buy-in, and creating a change strategy; these were similar to the challenges to interprofessional care noted at the FHT level. These concepts have also been noted in other studies as important for planning interprofessional change. ${ }^{29-31}$

FHTs who only received planning support through means of the online forum, and subsequently electronic mail were found to have low participation in the study. This may speak to a need for in-person knowledge translation 
support during planning for interprofessional change. Other research using Internet-based support only also notes high dropout rates. ${ }^{32-34}$

\section{Use of IRC}

In this study, the IRC was used to increase knowledge, to guide thinking, and to address problems around communication, team building, and goal setting. The primary reason for not using the IRC was lack of time. This finding is consistent with knowledge translation research that reports time as a key barrier. ${ }^{18,35}$

The IRC guides users through the process of interprofessional change presenting information and questions to consider at each step; however, pilot site participants experienced challenges applying the information from the IRC. The IRC resource, paired with meeting with investigators to facilitate application of material, did not provide the support needed for FHT representatives to create a plan for their identified interprofessional goal. The FHTs stated they needed more practical information; however, it remains unclear as to what would have been suitable to meet their needs. Interestingly, a desire for further education regarding interprofessional practice was noted as a system-level strategy to support interprofessional practice. Implementing this education may also support FHTs to apply information presented on the IRC.

The study found that there were existing team and organization issues that limited the interprofessional development of the FHTs; however, it remains unclear how these issues impacted on the use of the IRC, except for time. Other research in knowledge translation confirms that a key factor for successful knowledge translation is the capacity of the organization to use research. ${ }^{36}$ Future study may wish to explore how organizational issues specifically impact the use of online resources.

A key limitation of the study was our inability to explore differences between the pilot and non-pilot sites. The intent was to complete this analysis through the online forum; however, because of low participation, it was not possible. Additionally, because of stakeholder concerns with confidentiality and privacy, this analysis was also not possible for the summative survey. Another limitation was our inability to determine how the IRC could be better developed to provide the information that FHTs desire; although this was probed during the focus group, suggestions for improvement remained vague.

\section{Conclusion}

Based on the results of the study, it appears that online resource centers do have some value in knowledge translation for those working in primary health care when supported by in-person meetings. In exploring the planning of interprofessional change in primary health care teams, it was found that buy-in is a key challenge.

\section{Acknowledgments}

The authors acknowledge the administrators and providers in the family health teams who participated and generously gave their input, as well as the feedback received from the anonymous reviewers. This project received funding support from the Canadian Institutes of Health Research (CIHR) KTB 114398.

\section{Disclosure}

The authors report no conflicts of interest in this work.

\section{References}

1. Local Health System Integration Act. [homepage on the Internet]. Government of Ontario. 2006. Available from: http://www.e-laws.gov. on.ca/html/statutes/english/elaws_statutes_06104_e.htm. Accessed March 18, 2013.

2. HealthForceOntario. Implementing Interprofessional Care in Ontario: Final Report to the Interprofessional Care Strategic Implementation Committee. Ontario: HealthForceOntario; 2010. Available from: http:// www.healthforceontario.ca/UserFiles/file/PolicymakersResearchers/ ipc-final-report-may-2010-en.pdf. Accessed March 18, 2013.

3. Interprofessional Resource Centre. [homepage on the Internet]. Ontario: McMaster University; 2010. Available from: http://www. interprofessionalresourcecentre.ca. Accessed March 18, 2013.

4. D'Amour D, Oandasan I. Interprofessionality as the field of interprofessional practice and interprofessional education: an emerging concept. J Interprof Care. 2005;19(Suppl 1):8-20.

5. D'Amour D, Ferrada-Videla M, San Martin Rodriguez L, Beaulieu MD. The conceptual basis for interprofessional collaboration: core concepts and theoretical frameworks. J Interprof Care. 2005;19(Suppl 1): 116-131.

6. Canadian Institutes of Health Research [homepage on the Internet]. About knowledge translation. Public Works and Government of Canada; 2012. Available from http://www.cihr-irsc.gc.ca/e/29418.html. Accessed March 18, 2013.

7. Illes J, Chahal N, Beattie BL. A landscape for training in dementia knowledge translation (DKT). Gerontol Geriatr Educ. 2011;32(3): 260-272.

8. Korner EJ, Oinonen MJ, Browne RC. The power of collaboration: using Internet-based tools to facilitate networking and benchmarking within a consortium of academic health centers. J Med Syst. 2003;27(1):47-56.

9. Olson CA, Shershneva MB, Brownstein MH. Peering inside the clock: using success case method to determine how and why practicebased educational interventions succeed. J Contin Educ Health Prof. 2011;31(Suppl 1):S50-S59.

10. Bridges W. Managing Transitions: Making the Most of Change, 2nd ed. Cambridge, MA: Da Capo Press; 2003.

11. Kotter JP. Leading change: Why transformation efforts fail. Harv Bus Rev. 2007;85(1):96-103. 
12. MacPhee M. Strategies and tools for managing change. J Nurs Adm. 2007;37(9):405-413.

13. Rogers E. Diffusion of Innovations, 5th ed. New York: The Free Press; 2003.

14. Patterson C, Vohra J, Price D, et al. Interprofessional Resource Centre: a knowledge translation strategy. Advances in Medical Education and Practice. 2011;2:35-41.

15. Carter B. 'One expertise among many' - working appreciatively to make miracles instead of finding problems: Using appreciative inquiry as a way of reframing research. $J$ Res Nurs. 2006;11(1):48-63.

16. Sandelowski M. Whatever happened to qualitative description? Res Nurs Health. 2000;23(4):334-340.

17. Milne J, Oberle K. Enhancing rigor in qualitative description: a case study. J Wound Ostomy Continence Nurs. 2005;32(6):413-420.

18. Cabana MD, Rand CS, Powe NR, et al. Why don't physicians follow clinical practice guidelines? A framework for improvement. JAMA. 1999;282(15):1458-1465.

19. Davis DA, Thomson MA, Oxman AD, Haynes RB. Evidence for the effectiveness of CME. A review of 50 randomized controlled trials. JAMA. 1992;268(9):1111-1117.

20. Hunt JM. Barriers to research utilization. $J$ Adv Nurs. 1996;23(3): 423-425.

21. Dillman DA. Mail and Internet Surveys: The Tailored Design Method, 2nd ed. Hoboken, NJ: John Wiley \& Sons Inc; 2007.

22. Snell AJ, Briscoe D, Dickson G. From the inside out: the engagement of physicians as leaders in health care settings. Qual Health Res. 2011; 21(7):952-967.

23. Byrne M. Implementing performance management in the Irish health sector. Health Care Manag (Frederick). 2006;25(2):114-121.

24. Hayes C, Yousefi V, Wallington T, Ginzburg A. Case study of physician leaders in quality and patient safety, and the development of a physician leadership network. Healthc Q. 2010;13(Sp):68-73.

25. Humphreys J, Harvey G, Coleiro M, et al. A collaborative project to improve identification and management of patients with chronic kidney disease in a primary care setting in Greater Manchester. BMJ Qual Saf. 2012;21(8):700-708.
26. Russ SA, Hanna D, DesGeorges J, Forsman I. Improving follow-up to newborn hearing screening: a learning-collaborative experience. Pediatrics. 2010;126(Suppl 1):S59-S69.

27. Canadian Interprofessional Health Collaborative. A National Interprofessional Competency Framework. Vancouver, Canada: University of British Columbia; 2010. Available from http://www.cihc.ca/ files/CIHC_IPCompetencies_Feb1210.pdf. Accessed March 18, 2013.

28. Braithwaite J, Westbrook M, Nugus P, et al. A four-year, systems-wide intervention promoting interprofessional collaboration. BMC Health Serv Res. 2012;12:99.

29. Hendy J, Barlow J. The role of the organizational champion in achieving health system change. Soc Sci Med. 2012;74(3):348-355.

30. Shaw EK, Howard J, Etz RS, Hudson SV, Crabtree BF. How team-based reflection affects quality improvement implementation: a qualitative study. Qual Manag Health Care. 2012;21(2):104-113.

31. Yeager S. Interdisciplinary collaboration: the heart and soul of health care. Crit Care Nurs Clin North Am. 2005;17(2):143-148.

32. Eysenbach G. The law of attrition. J Med Internet Res. 2005; 7(1):e11.

33. McCabe MP, Price E. Attrition from an Internet-based psychological intervention for erectile dysfunction: who is likely to drop out? J Sex Marital Ther. 2009;35(5):391-401.

34. Melville KM, Casey LM, Kavanagh DJ. Dropout from Internet-based treatment for psychological disorders. Br J Clin Psychol. 2010; 49(Pt 4):455-471.

35. Cilenti D, Brownson RC, Umble K, Erwin PC, Summers R. Informationseeking behaviors and other factors contributing to successful implementation of evidence-based practices in local health departments. J Public Health Manag Pract. 2012;18(6):571-576.

36. Hamel N, Schrecker T. Unpacking capacity to utilize research: a tale of the Burkina Faso public health association. Soc Sci Med. 2011; 72(1):31-38.
Advances in Medical Education and Practice

\section{Publish your work in this journal}

Advances in Medical Education and Practice is an international, peerreviewed, open access journal that aims to present and publish research on Medical Education covering medical, dental, nursing and allied healthcare professional education. The journal covers undergraduate education, postgraduate training and continuing medical education

\section{Dovepress}

including emerging trends and innovative models linking education, research, and healthcare services. The manuscript management system is completely online and includes a very quick and fair peer-review system. Visit http://www.dovepress.com/testimonials.php to read real quotes from published authors. 